\title{
What is Affirmative Action?
}

\section{Carl Cohen}

Confusion in the sphere of affirmative action abounds. Affirmative action was introduced in the 1960s to support the quest for racial justice, to help American society overcome its painful history of outright racial oppression in its early years, and racial discrimination in more recent years. Its goal was, and remains, to make our union more perfect. No reasonable person should fail to honor it. In its original and classical sense it is rightly practiced and justifiably defended.

Affirmative action takes many forms, of course. There is no limit to the ways in which we can become, as a society, more fair. Taking concrete steps, affirmative steps that aim to right earlier wrongs, is everywhere to be honored. This is true even if the steps taken are small and not widely seen. Some examples:

Private companies, in their hiring, have often adopted practices that discriminate against blacks, or against women. Such practices may have arisen as the product of outright discrimination by bad men. Or they may have been adopted without malicious intent, becoming company policy without the general recognition of their injustice. A company that sets out now, deliberately, to review its hiring practices with the aim of identifying and eliminating those having discriminatory outcomes, is surely engaging in affirmative action.

Examinations, given in schools and universities, whose results determine the award of prizes or other honors, are often discriminatory because of some unrecognized features. Examination questions may suppose familiarity with certain unstated aims or standards employed in some cultures but not others, or may suppose familiarity with a vocabulary that some minorities may not know. The review of examinations with the aim of eliminating questions 
that incorporate such unfair suppositions is surely to be commended. Those deliberate efforts are also rightly thought of as affirmative action.

In contexts like these, affirmative action is simply a return to fundamental principles of equality; no special justification for such steps is called for.

But there are some circumstances in which the policies adopted, with equally honorable objectives, are understandably controversial. This is common where the aim is that of fairness in admission to some institutions. Preferential admission policies, called "affirmative action" in American universities, are widespread. These policies are explosively controversial because there are deep disagreements about what is required to achieve fairness.

One common view relies on comparative numbers. Blacks constitute 14 percent of the American population. Fairness therefore requires that approximately 14 percent of the Congress be black. Plausible. Does fairness also require that 14 percent of the graduate students at some university be black? That 14 percent of the performers in the New York Philharmonic Orchestra be black? Or that 14 percent of our professional basketball players be black? Actual percentages depend on many factors, of course. Preparation of the young for classical music performance is more common in some cultural groups than in others. Winning seats in the finest orchestras is, as a matter of evident fact, more common for those who have undergone that early musical training. This imbalance is not unfair. More than 60 percent of our professional basketball players are black. This imbalance likewise is not unfair. Professional ball players win their places because of their early training; they are highly skilled and thought likely to advance their team's goal of winning ball games. In these and in many other spheres, numerical group imbalances are the unavoidable consequences of different cultural emphases. Skills, not skin color, generally determine the outcome. To demand that places in any competitive arena be distributed proportionately by race is racism, not fairness.

In a fair society, members of different races are not treated differently, some more generously and others less, because of their race. Where the opportunity to compete is open equally to all, skin color is simply not relevant. Equal treatment of the races is an absolute demand of justice.

Therefore, we ought not tolerate any system in which some are advantaged because of their race. Affirmative action, properly understood, is honored because it advances racial equality. Unequal treatment, in the name of 
affirmative action, cannot be defended. However honorable the objective, the unequal treatment of the races must be condemned.

That is where we are. Unhappily, we have recently come to name some departures from justice as "affirmative action.” Today, in common parlance, "affirmative action" denotes some set of policies or programs that give some racial groups preference. Such policies turn justice upside down.

"Well," (say the defenders of this use of the term "affirmative action"), "this departure from the demand for racially equal treatment is required for the sake of fairness." The system, they remind us, has long been unfair to minorities; reverse unfairness is (they suppose) therefore justifiable now.

It is not. Past injustice in one sphere cannot justify present injustice in another. There is, indeed, a continuing demand that the opportunity to compete be genuinely equal. In university admission, as in every sphere, minority members must not suffer disadvantage. Right. But in the competition for admission to American universities today, that demand is met. Racial minorities are no longer disadvantaged. In this context, and others like it, "affirmative action," taken here to mean "giving preference to members of some racial group previously disadvantaged,” is common. Such policies are simply wrong, legally and morally.

Affirmative action has honorable roots and honorable goals. But the term has become, sadly, the name of injustice. We seek to eliminate racial preference in every sphere, of course. Bearing that goal in mind, we should proudly return to affirmative action as it was originally understood-concrete steps, just steps, taken for the enlargement and improvement of our union. 